\title{
CURSO DE METODOLOGIA INCLUSIVA PARA PROFESSORES DO MUNICÍPIO DE ABEL FIGUEIREDO - PARÁ
}

\author{
Gabriel Gonçalves Monteiro \\ Universidade Estadual do Norte do Paraná \\ gabrielmonteiro7777@hotmail.com \\ Tiago Moisés de Oliveira \\ Universidade Estadual do Norte do Paraná \\ gabrielmonteiro7777@yahoo.com.br \\ Amanda Suelen Fiorillo \\ Universidade Estadual do Norte do Paraná \\ amandafiorillo@hotmail.com \\ Everson Olandini Alves \\ Universidade Estadual do Norte do Paraná \\ eversonorlandini@hotmail.com \\ Jamille Mariana de Oliveira Marques \\ Universidade Estadual do Norte do Paraná \\ jamillemomarques@hotmail.com
}

\author{
Leticia Nascimento Gonçalves de Oliveira \\ Universidade Estadual do Norte do Paraná \\ leticiangoliveira@gmail.com
}

Marco Antonio Turatti Junior Universidade Estadual do Norte do Paraná juniorturatti@hotmail.com

Mariza Fordelone Rosa Cruz Universidade Estadual do Norte do Paraná mfordellone@uenp.edu.br

Vanessa Cristina Godoi de Paula Universidade Estadual do Norte do Paraná vanessa.cgodoi@hotmail.com

Erro! Fonte de referência não encontrada

No município de Abel Figueiredo - Pará foi realizado o curso de metodologia inclusiva para professores da rede pública que atendem as escolas urbanas e rurais. $\mathrm{O}$ mesmo teve como prioridade capacitar professores perante os requisitos mínimos da licenciatura. Durante cinco dias foi realizado o curso de metodologia inclusiva, este contendo 15 horas de duração e abrangendo todos os aspectos da licença de ensino. A realização do mesmo capacitou os professores a realidade atual das escolas e os aprimorou ao desenvolvimento de suas metodologias. Com o mesmo, foi observada a demonstração do interesse pelos professores em aumentarem suas habilidades de ensino dentro de uma sala de aula. O curso de metodologia inclusiva foi realizado aos dias 13,14, 15, 21 e 22 de julho durante a operação Itacaiúnas sendo esta os dias 16 de julho a 01 de agosto de 2015.

Palavras-chave: Metodologia inclusiva. Professores. Rede pública. Escola urbana e rural

\section{INCLUSIVE METHODOLOGY COURSE FOR TEACHERS OF ABEL FIGUEIREDO CITY - PARÁ}

Abstract

In Abel Figueiredo city - Pará the inclusive methodology course was done for teachers of public education who attend rural and urban schools. It had as priority to train teachers towards the minimum requirements of teaching license. During five days the inclusive methodology course was done, it had 15 hours as duration and it covered all aspects of teaching license. The realization of this course provides for teachers the real situation of the current schools and it approaches them on their methodology abilities. So, on this course was observer the demonstration of teacher's interests on improving their teaching abilities inside a class room school. The inclusive methodology course was done on July 13, 14, 15, 21 and 22 during the Itacaiúnas operation that was during July 16 and August 1 st 2015.

Keywords: Inclusive methodology. Teachers. Public teaching. Urban and rural schools. 


\section{EXIENHEHI \\ 15:-

\section{CURSO DE METODOLOGÍA INCLUYENTE PARA PROFESSORES EN EL MUNICIPIO DE ABEL FIGUEIREDO - PARÁ}

\section{Resumen}

En el municipio de Abel Figueiredo - Pará, se llevó a cabo el curso de metodología incluyente para los profesores de escuelas públicas que sirven las escuelas urbanas y rurales. La misma tuvo como prioridad formar a los profesores em los requisitos mínimos de la titulación. Durante cinco días del curso se llevó a cabo en una metodología incluyente, esto contiene 15 horas de duración y que abarque todos los aspectos de la licencia de enseñanza. La realización de los profesores, incluso entrenados para presentar la realidad de las escuelas y mejorado el desarrollo de metodologías. Con el mismo se observó la demostración de interés por los profesores aumentar sus habilidades de enseñanza en el aula. El curso de metodología incluyente se celebró el día 13, 14, 15, 21 y 22 de julio durante Itacaiúnas operación y el día de hoy 16 julio hasta 1 agosto 2015.

Palavras clave: Metodología incluyente. Profesore. Educacion pública. Escuela urbana y rural 
Curso de metodologia inclusiva para professores do município de Abel Figueiredo - Pará

\section{INTRODUÇÃO}

Entre as necessidades fundamentais ao ser humano contemporâneo, reconhecidos em leis e documentos, se encontram os chamados direitos à educação. O direito à educação é parte de um conjunto de direitos chamados de direitos sociais e constitucionais, que têm como inspiração o valor da igualdade entre todas as pessoas em seus respectivos territórios (CONSTITUIÇÃO, 1988).

No Brasil este direito apenas foi reconhecido na constituição federal de 1988, pois antes disso, o estado não tinha a obrigação formal de garantir a educação de qualidade a todos os brasileiros, o ensino público era tratado como uma assistência, um amparo dado àqueles que não podiam pagar. Durante a constituinte de 1988 as responsabilidades do estado foram repensadas e promover a educação fundamental passou a ser seu dever (CONSTITUIÇÃO, 1988).

A constituição federal de 1988 é o conjunto de normas que regula o estado brasileiro. Nela, há normas que estabelecem quais são e as funções e competências dos diferentes órgãos do estado (poderes judiciário, legislativo, executivo, municípios, estados, união, defensoria pública, ministério público, entre outros) (CONSTITUIÇÃO, 1988).

Além de dizer como o estado tem que funcionar e as relações que podem se estabelecer entre os diferentes órgãos e poderes, a constituição também estabelece objetivos a serem alcançados pela sociedade como um todo, e estabelecem quais são as responsabilidades do estado para que tais objetivos sejam alcançados (CARDOSO, 1996).

A educação é um direito garantido pela constituição federal de 1988. Logo em seu art. $6^{\circ}$, o documento jurídico mais importante do nosso país diz que a educação - juntamente com a moradia, o trabalho, o lazer, a saúde, entre outros - é um direito social (CONSTITUIÇÃO, 1988). Ou seja, não é um favor do estado para as pessoas. Pelo contrário, como é entendida como um direito, a educação pode e deve ser exigida dos órgãos competentes quando esse direito for violado ou desrespeitado.

O fato de a constituição citar ainda a qualificação para o trabalho não significa ser esse seu objetivo principal, como muitas vezes se tenta interpretar. A educação profissional, para respeitar sua natureza de direito social constitucional, precisa estar integrada à concepção ampla de educação, possibilitando a inserção autônoma e qualificada no mundo do trabalho (COLLOR, 1990).

Não se nega que as necessidades da vida e o avanço tecnológico exijam que as pessoas estejam cada vez mais qualificadas para o trabalho e que uma das formas de se conseguir isso é por meio da educação. No entanto, o desenvolvimento da pessoa implica muitas outras 
dimensões, principalmente o pleno desenvolvimento das capacidades humanas e o consequente preparo ao exercício da cidadania.

Além da constituição federal, de 1988, existem ainda duas leis que regulamentam e complementam a do direito à educação (COLLOR, 1990): o estatuto da criança e do adolescente (ECA), de 1990; e a lei de diretrizes e bases da educação (LDB), de 1996 (CARDOSO, 1996). Juntos, estes mecanismos abrem as portas da escola pública fundamental a todos os brasileiros, já que nenhuma criança, jovem ou adulto pode deixar de estudar por falta de vaga.

Assim, durante a operação Itacaiúnas inserida pelo projeto Rondon no ano de 2015 durante os dias 16 de julho a 01 de agosto, os discentes Gabriel Gonçalves Monteiro e Tiago Moisés de Oliveira da Universidade Estadual do Norte do Paraná realizaram o curso de metodologia inclusiva para professores da rede pública que atendem as escolas urbanas e rurais no município de Abel Figueiredo - Pará. Este curso teve como duração uma carga horária de 15 horas, realizado durante duas semanas, especificamente aos dias 13, 14, 15, 21 e 22 de julho das 9h às $12 \mathrm{~h}$, na Escola Estadual de Ensino Médio Professor Helio Frota Lima em Abel Figueiredo - Pará.

A importância da realização e da ministração do curso de metodologia inclusiva se fez necessário por avaliar e discutir sobre os casos do sistema educacional local e sua reprodutiva repercussão nos adolescentes e jovens do município para um reconhecimento da área. Deste modo, a avalição da situação da região com a referida proposta foi possível na formação e aprimoração dos métodos educacionais de se abordar e se ensinar.

O levantamento destas possibilidades estreitou o vínculo entre professores e alunos. Assim, a apresentação destas maneiras de se abordar e ensinar o aluno levando em conta seu conhecimento prévio sobre o assunto foi efetuado para desenvolver a construção de um conhecimento significativo, e que se fez harmônica pela consolidação dos docentes do município de Abel Figueiredo - Pará.

\section{MATERIAIS E MÉTODOS}

O curso de metodologia inclusiva possuiu 15 horas de duração sendo este realizado em duas semanas, no período das $9 \mathrm{~h}$ às $12 \mathrm{~h}$ na Escola Estadual de Ensino Médio Professor Helio Frota Lima em Abel Figueiredo - Pará. A primeira semana, sendo esta durante os dias 13, 14 e 15 de julho, obteve como temas abordados a contextualização da escola urbana e dos métodos pedagógicos referentes ao ensino. Consequentemente a segunda semana, sendo esta durante os 
dias 21 e 22 de julho, obteve como temas abordados a contextualização da escola rural e das compreensões de cidadania do aluno perante a sociedade. Os estudantes da Universidade Estadual do Norte do Paraná de graduação em bacharelne licenciatura em ciências biológicas; Gabriel Gonçalves Monteiro e de licenciatura em história; Tiago Moisés de Oliveira ministraram o curso de metodologia inclusiva para professores da rede pública que atendem escolas urbanas e rurais do município de Abel Figueiredo - Pará.

Especificamente durante a primeira semana de ministração do curso de metodologia inclusiva, os temas abordados trataram dos aspectos da escola urbana e dos métodos pedagógicos referentes ao ensino. Ao dia 13 de julho os tópicos abordados estavam dispostos ao curso de capacitação de professores profissionais juntamente com as técnicas metodológicas de ensino. Nesses temas foram conceituados os tipos de professores que existem no Brasil (IG, 2013), a organização básica de uma sala de aula, a postura do professor e a interação do mesmo com o aluno. Consequentemente referentes aos métodos pedagógicos de ensino (ilustração 1), se fez necessária a contextualização histórica do ensino no Brasil, e a compreensão das metodologias de ensino perante a aprendizagem, construtivismo e as técnicas de ensino no país.

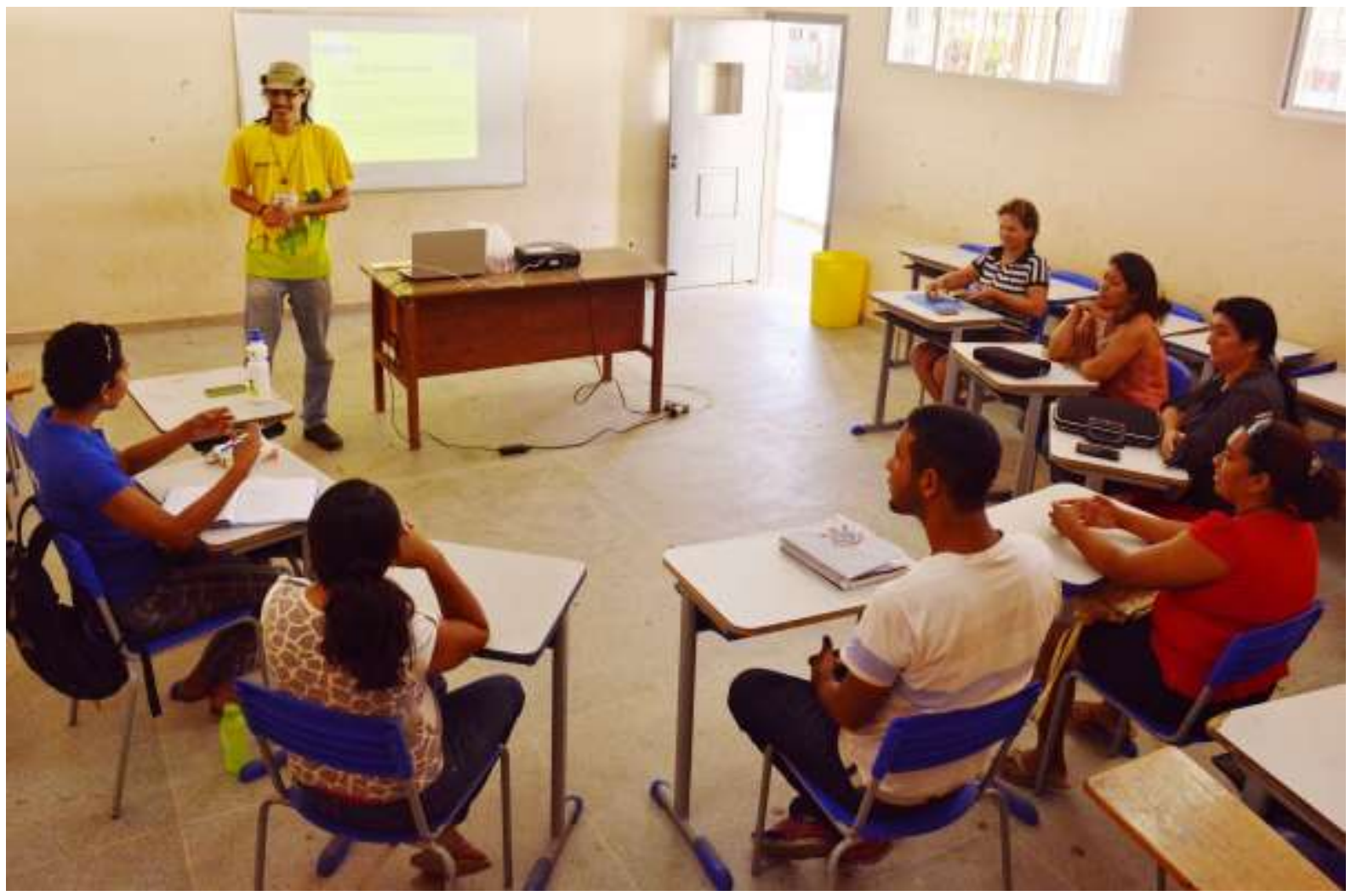

Ilustração 1 - Palestra dos métodos pedagógicos de ensino. Fonte: Operação Itacaiúnas, 2015.

Durante o dia 14 de julho os tópicos abordados conectaram os princípios da ética, cidadania e da interdisciplinaridade com as técnicas de aprendizagem e atividades lúdicas que 
podem ser realizadas em sala de aula. Perante a ética e cidadania se fez necessário o debate aprofundado sobre a educação cívica e os valores humanos presentes na escola, estes interligados com a constituição que a escola pode promover. Decorrente do mesmo, a definição e exemplificação da interdisciplinaridade se fizeram necessária. Em adição exemplos didáticos foram abordados referentes às técnicas de aprendizagem comparando-os com a aprendizagem mecânica e a aprendizagem assimilativa, e qual a importância de cada uma para o aprendizado do aluno. Os conceitos de mapa mental e brainstorm também foram abordados, estes associados com as atividades lúdicas e dinâmicas em sala de aula que o professor pode desenvolver para facilitar o ensino a sala de aula.

Encerrando a primeira semana do curso de metodologia inclusiva, no dia 15 de julho foi tratada a relação da importância da abordagem de gêneros na escola associados com a educação sexual (ilustração 2). Os conceitos até então considerados como tabus sociais foram discutidos relacionados com os elementos da sexualidade, com a importância da conexão da PLC 122 e da metodologia da abordagem deste tema na escola. Assim, referente à educação sexual, se fez necessária à compreensão por parte do entendimento que o aluno necessita obter sobre o tema. Sendo estes relacionados à escola perante o discernimento do aluno referente a sexo e sexualidade, homossexualidade e homofobia, aparelhos reprodutores, menstruação e tensão prémenstrual, gravidez, métodos contraceptivos e doenças sexualmente transmissíveis.

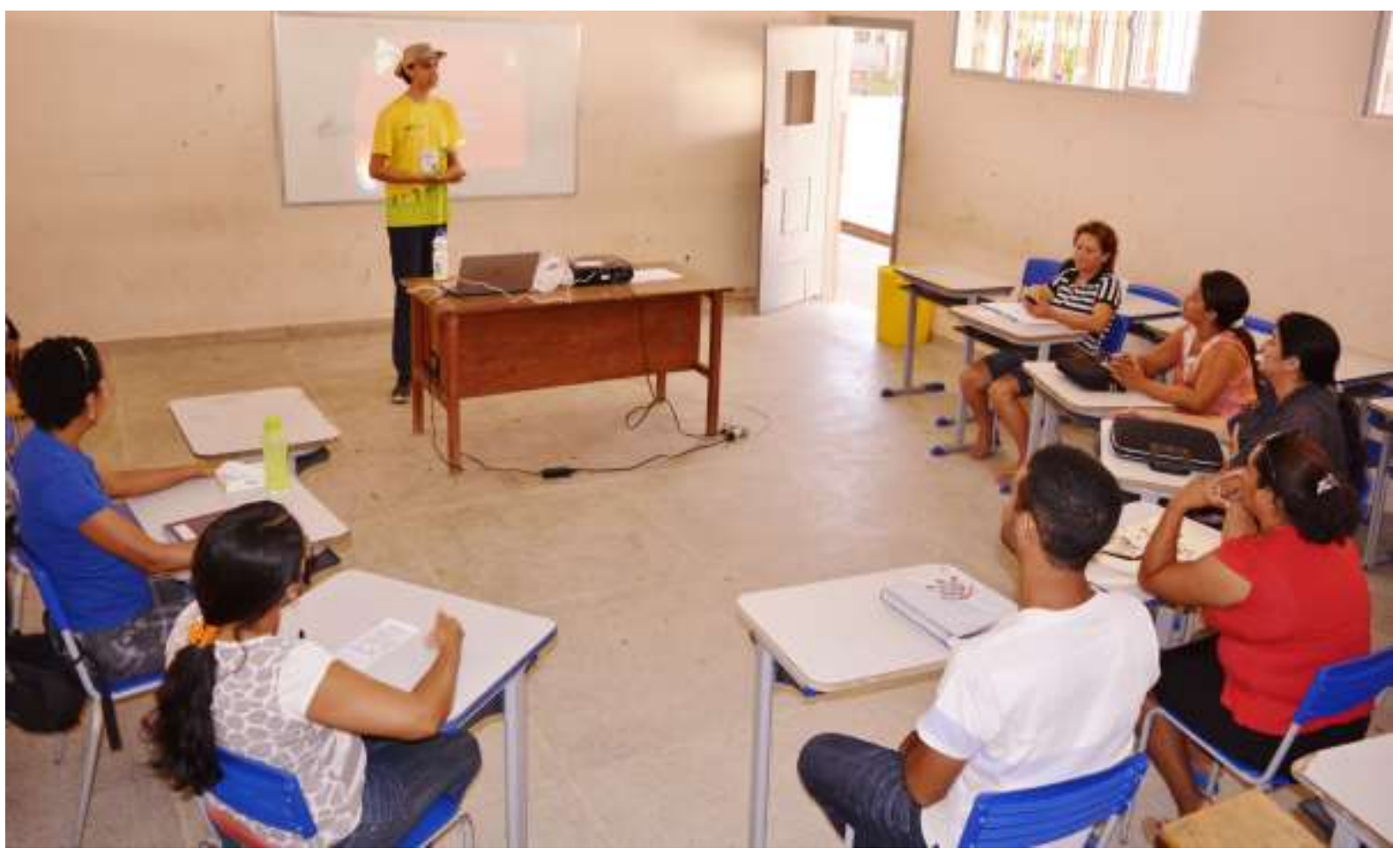

Ilustração 2 - Palestra de educação sexual para alunos.

Fonte: Operação Itacaiúnas, 2015. 
Curso de metodologia inclusiva para professores do município de Abel Figueiredo - Pará

Caracterizando a segunda semana de ministração do curso de metodologia inclusiva, os temas abordados trataram dos aspectos da escola rural e das compreensões de cidadania do aluno a sociedade. Ao dia 21 de julho os tópicos abordados estavam divididos em educação do campo I e cidadania. Ao desenvolvimento do tema de educação do campo I, foi tratado o significado e importância do movimento dos sem terra, abordando a sua história, a reforma agrária e o seus objetivos. Associado a estes temas foram exemplificados a educação pedagógica dentro do movimento, as suas bases com seus processos educativos, as suas matrizes pedagógicas e a escola no movimento. Interligados ao conceito de cidadania, foram relacionados os princípios de valoração, moral, ética, direitos, dimensões, desigualdades sociais e justiça, sendo todos desenvolvidos ao ambiente escolar.

Encerrando então o curso de metodologia inclusiva, ao dia 22 de julho foi abordada a educação do campo II e meio ambiente e a entrega de certificados (ilustração 3).

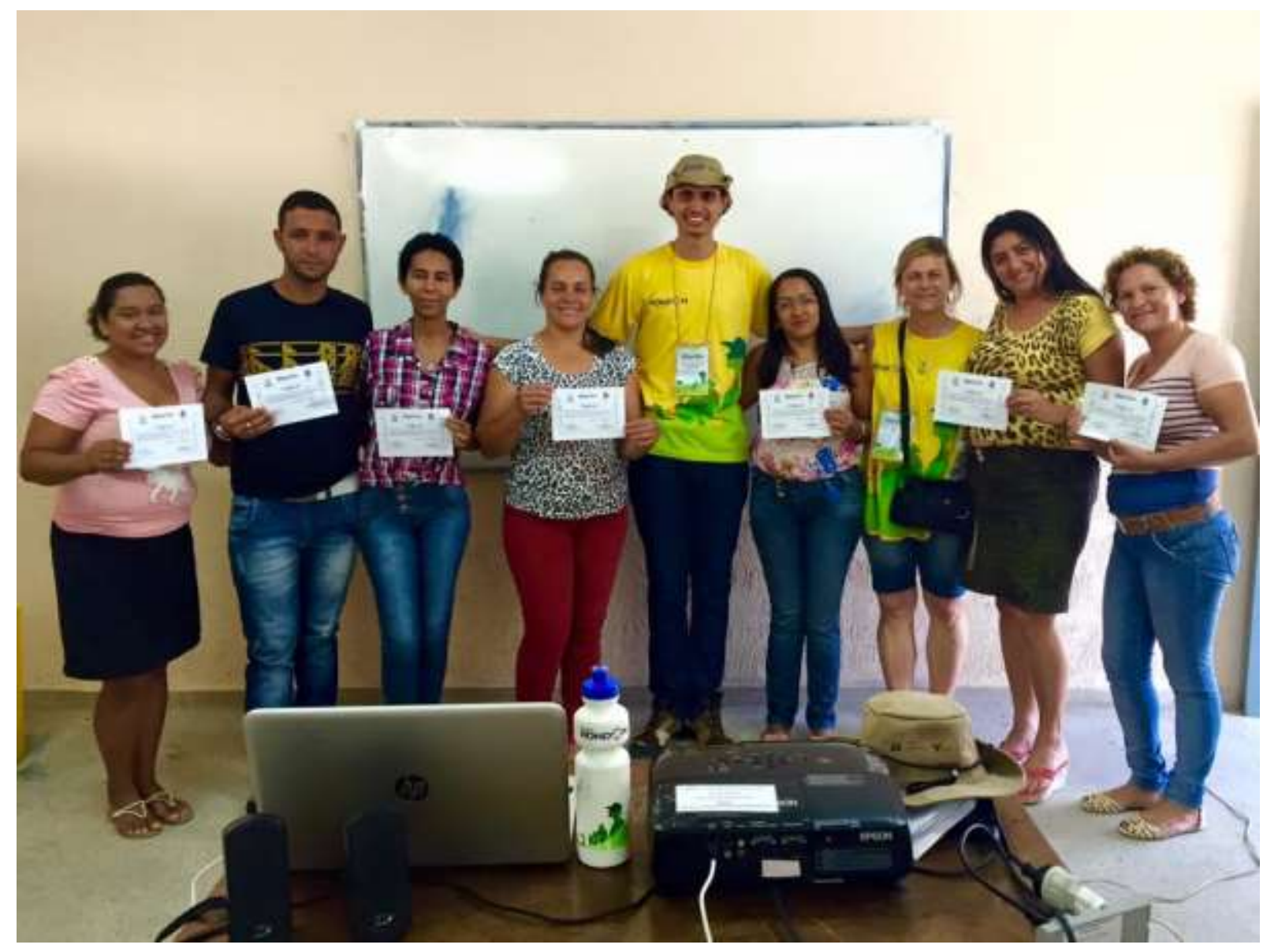

Ilustração 3 - Entrega de certificados. Fonte: Operação Itacaiúnas, 2015.

Em conclusão da educação do campo, o contexto histórico estava referente à educação rural nas constituições federais, abordando então a concepção de campo e de educação e suas 
Curso de metodologia inclusiva para professores do município de Abel Figueiredo - Pará

origens. Como princípio de comparação entre a educação urbana e a educação do campo, foram relacionadas à importância da educação do campo e das escolas, assim como os grandes desafios do século XXI contrapondo com seus limites. Em conclusão, os temas ambientais foram apresentados e associando-os com a importância da escola pela conscientização dos alunos referentes à sustentabilidade e conservação ambiental, meio ambiente, recursos hídricos sanitarismo e controle ambiental de vetores, manejo de resíduos sólidos, uso e ocupação do solo, emissões atmosféricas e saneamento ambiental rural. Ao final do curso foram distribuídos certificados correspondendo com a quantidade de horas assistidas por cada ouvinte juntamente com um CD contendo todas as apresentações em multimídia.

\section{RESULTADOS E ANÁLISES}

Durante a execução do curso de metodologia inclusiva para professores da rede pública do município de Abel Figueiredo - Pará, uma oportunidade de adquirir novos conceitos e conhecimentos como professores foi observada. Consideravelmente, este curso proporcionou o aprendizado recíproco entre palestrantes e ouvintes, pois ambos possuíam novas atribuições e ensinos a serem transmitidos. Ao longo de todos os dias do curso de metodologia inclusiva, o mesmo apresentou análises específicas quando se refere a determinados termos conceituais. A observação foi referida pelos resultados desenvolvidos pelos palestrantes e pelos ouvintes.

Ao primeiro dia de palestra quando se tratou da relação de um curso de capacitação de professores profissionais houve um destaque aprofundado perante alguns requisitos quanto à metodologia empregada para o desenvolvimento de uma aula. Assim, consta como nova atribuição e detalhamento específico perante o roteiro que um professor deve desenvolver dentro de sala de aula. Outros tópicos de impacto foram analisados, como por exemplo, o manejo do tempo que um professor deve obter em sala de aula e a voz e dicção apropriada para o desenvolvimento de sua atividade. Dentre muitos conceitos e termos abordados, destaca-se a importância da vestimenta adequada de um professor e como um dos últimos temas trabalhado, a importância da observação do comportamento dos alunos quanto ao bullying. Em adição, foi observada a atenção perante formas de abordagens pedagógicas e suas aplicações no ensino escolar no contexto social local do aluno. Através dos métodos de educação até então discutidos foi observado os gérmens de emancipação, autonomia e integração social entre a comunidade escolar. 
Durante o segundo dia do curso de metodologia inclusiva, ao contexto de ética, cidadania e interdisciplinaridade foi observado à compreensão dos professores perante o tema e a associação da importância da abordagem dos mesmos dentro de uma sala de aula. Além de exercitarem as práticas do processo educativo, foi constado também durante a ministração do mesmo, a concepção e responsabilidade de associarem a importância da vida diante do mundo e as capacidades que se deve desenvolver para a execução destas práticas. Associado a esta relação de tipos de aprendizagem, foi constatado a partir dos professores a compreensão da diferenciação de aprendizagem mecânica e aprendizagem assimilativa. Um dos pontos mais fortes conceituados pelos mesmos foi à importância da repetição para a aprendizagem mecânica e como este fator implica para a facilitação do aluno aprender determinado assunto a partir desta metodologia de ensino. Durante a associação da aprendizagem assimilativa, foi observado perante os professores a relação da importância da compreensão do raciocínio e os estímulos que o mesmo pode fornecer durante a execução desta metodologia. No entanto, durante um desafio de raciocínio lógico para os professores, os mesmos não conseguiram completar, mesmo concordando com a importância que o mesmo desafio fornece aos alunos. Um dos pontos mais altos observados durante a execução do curso foi o aprendizado de novas técnicas de atividades lúdicas e dinâmicas em aula, pois estas foram desenvolvidas como se os professores fossem os alunos de suas turmas, assim o ato desta atividade fez com que os professores percebessem a importância de desenvolverem técnicas novas de descontrações em uma sala de aula.

Ao terceiro dia do curso de metodologia inclusiva, perante os assuntos de diversidade de gênero e educação sexual, foi apresentado para os educadores o incentivo de levar para as salas de aula assuntos e temas envolvendo as questões de gêneros e educação sexual. Contudo, foi gerado debates e discussões onde a partir delas surgiram orientações e direções corretas sobre o que é e o que não é correto afirmar sobre o tema que foi discutido. Houve um levantamento em massa onde que os temas que são considerados tabus perante a sociedade, estes dificultam o trabalho dos educadores quando abordados em sala de aula. Todavia, em muitas histórias compartilhadas sobre as experiências dos professores e a relação da abordagem do tema de sexualidade perante muitas vezes aos responsáveis dos alunos, ainda se encontra uma barreira presente na sociedade. Um dos pontos fortes presentes da discussão foi à relação do homossexualismo dentro da escola. Quando o tema foi abordado, todos os professores mantiveram a conduta de respeito a esta diferenciação de atração de gêneros, no entanto, quando foi realizada uma suposição de possuir um membro familiar homossexual, houve várias atribuições a esta realidade, sendo de aceitação e rejeição. Além do mais, foi ressaltada a importância da apresentação e explicação dos métodos 
contraceptivos com exemplos levados para a palestra e sua importância contra prevenção de doenças sexualmente transmissíveis.

O quarto dia de curso de metodologia inclusiva a partir de então esteve voltado para as questões da escola rural e da importância deste ensino e suas metodologias específicas. Houve a apresentação e compreensão dos objetivos do MST, onde por parte dos professores, os mesmos descreveram a importância deste movimento que esta além da reforma agrária, assim foi proposta que as transformações sociais ao MST estão conectadas com os aspectos de inclusão social. Partindo dos professores, os mesmo diferenciaram a pedagogia do MST sendo caracterizado em cinco momentos, a pedagogia da luta social, a pedagogia da organização coletiva, a pedagogia da terra, a pedagogia da cultura e a pedagogia da história. E interligados com os princípios de cidadania, proveniente dos professores, os mesmo realizaram a diferenciação da ética, moral e da valoração de um sujeito qualquer presente em uma sociedade. Todos os professores concordaram pelas relações que o estado atribui com as práticas de um cidadão deve oferecer a sua comunidade, e que a moral e a ética estarão associadas com o meio de convívio do indivíduo, sendo este cívico, familiar, social, político ou religioso. No entanto, todos os professores mantiveram a conduta de que um cidadão independente dos princípios que ele vive, estes devem estar em acordo para que forneça um ambiente harmônico dentro de uma sociedade, ou seja, com que seus atos não tragam consequência para qualquer cidadão.

Ao quinto e último dia do curso de metodologia inclusiva, foi ressaltado e concluído as relações da escola do campo e da correlação que a mesma fornece para a escola da cidade. Durante a concepção da escola do campo, os professores tomaram como bases a compreensão a partir do espaço da produção de economia, e como o meio urbano esta totalmente dependente do meio rural. No entanto por se tratar de quesitos de inclusão social, os professores tomaram como bases os princípios mínimos que os mesmos devem desenvolver perante as situações de confronto social entre o meio rural e urbano. Assim, os mesmo analisaram os aspectos de identificação do meio, e disposição para pensar diferente. Consequentemente se faz necessário para que o professor seja sujeito e sinta-se sujeito e queira ser sujeito do processo pedagógico perante qualquer realidade estudantil. Os docentes concordaram que nesta relação, o princípio da interdisciplinaridade, deve estar automaticamente implementada nas questões pedagógicas. E que o professor deve saber definir os conceitos dos conhecimentos locais e científicos a serem trabalhadas, bem como as estratégicas metodológicas, a avaliação contínua, e as propostas para cada momento pedagógico em diversas maneiras. Em conclusão, durante a apresentação das questões de sustentabilidade e conservação ambiental, houve um acordo com todos os professores da importância do tema que deve ser abordado em sala de aula. No entanto, os 
Curso de metodologia inclusiva para professores do município de Abel Figueiredo - Pará

princípios ambientais estão intimamente relacionados com a conduta de um cidadão. Assim, foi concluído de acordo com os professores, que os pressupostos ambientes sendo do meio urbano ou rural, estão interligados ao saneamento básico, pois com o manejo correto do mesmo ocorre um melhoramento significativo perante a saúde pública.

\section{CONSIDERAÇÕES FINAIS}

Assim como apresentado o direito à educação esta presente em todos os territórios brasileiro. A partir da constituição federal em 1988, este direito foi reconhecido por lei, garantindo então a todos o valor a esta igualdade de ensino. Assim, por ser garantida pela Constituição Federal em 1988 a educação esta assegurada a todos os brasileiros. A educação como um todo tem como visar à qualificação para um bom desenvolvimento profissional qualificado ao mercado de trabalho.

O estatuto da criança e do adolescente (ECA) de 1990, juntamente com a lei de diretrizes e bases da educação (LDB) de 1996, visa abranger mecanismos apropriados para qualquer criança, jovem ou adulto leis que complementam o direito à educação.

Assim, o curso de metodologia inclusiva realizado no município de Abel Figueiredo Pará durante os dias 13, 14, 15, 21 e 22 de julho foi uma oportunidade para que os professores do município de Abel Figueiredo - Pará pudessem analisar as suas próprias condutas como docentes e observar a real realidade de suas salas de aula. Ao conceito de capacitação profissional a auto avaliação de ser um professor foi essencial para a análise de suas condutas, assim como suas aplicações nas abordagens pedagógicas. Seus processos de análise perante direitos e deveres do estudante e da associação dos tipos de aprendizagem também foram aspectos importantes para atribuição a suas linhas de ensino. Ao fator de ensino sexual e abordagens de gêneros na escola, a importância desta discussão levou aos docentes a oportunidade de abordarem este tema com seus alunos. Assim como o contexto de escola rural e suas metas e a contextualização de cidadania e meio ambiente vieram à tona para fixarem ao currículo estudantil.

A execução do curso de metodologia inclusiva foi de extrema importância por abranger conceitos básicos que muitas vezes são desvalorizados por docentes, com isto durante a apresentação do mesmo, a inserção dos temas apresentados foi essencial para que os professores descobrissem suas novas habilidades de ensino. 


\section{REFERÊNCIAS}

ALENCAR, C. e GENTILI, P. EDUCAR NA ESPERANÇA EM TEMPOS DE DESENCANTO. Rio de Janeiro, Petrópolis: Editora Vozes, p.87, 2001.

BEAUVOIR, S. O SEGUNDO SEXO. Vol 2: A Experiência Vivida, Difusão Européia do Livro, 1967.

CARDoso, F. H. LEI DE DIRETRIZES E BASES DA EDUCAÇÃO NACIONAL (LDB). Brasília, DF: $185^{\circ}$ da Independência e $108^{\circ}$ da República, 1996. Disponível em: http://portal.mec.gov.br/arquivos/pdf/ldb.pdf. Acesso em: 7 out. 2015.

COLEÇÃO MANUAL DE DIREITOS HUMANOS. DIREITO HUMANO À EDUCAÇÃO. São Paulo, SP - volume 07, 2011. Disponível em: http://www.direitoaeducacao.org.br/wpcontent/uploads/2011/12/manual dhaaeducacao 2011.pdf. Acesso em: 7 out. 2015.

COLLOR, F. ESTATUTO DA CRIANÇA E DO ADOLESCENTE (ECA). Brasília, DF: LEI $\quad \mathrm{N}^{\circ}$ 8.069, DE 13 DE JULHO DE 1990. Disponível em: http://www.planalto.gov.br/CCIVIL 03/leis/L8069.htm. Acesso em: 7 out. 2015.

CONSTITUIÇÃO. CONSTITUIÇÃO DA REPÚBLICA FEDERATIVA DO BRASIL. Brasília, DF: Senado Federal: Centro Gráfico, 292 p, 1988. Disponível em: http://www.planalto.gov.br/ccivil 03/constituicao/constituicao.htm. Acesso em: 7 out. 2015. 